\title{
Preliminary GPS results and a possible neotectonic interpretation for South Korea
}

\author{
Pil-Ho Park ${ }^{1,2}$, Ueechan Chwae ${ }^{3}$, Yong-Won Ahn² ${ }^{2}$ and Kyu-Hong Choi \\ ${ }^{1}$ Department of Astronomy, Yonsei University, Seoul 120-749, Korea \\ ${ }^{2}$ Korea Astronomy Observatory, 61-1, Whaam-dong, Yusong-gu, Taejon 305-348, Korea \\ ${ }^{3}$ Korea Institute of Geoscience and Mineral Resources, 30, Kajung-dong, Yusong-gu, Taejon 305-350, Korea \\ (Received May 1, 2001; Revised July 9, 2001; Accepted July 10, 2001)
}

\begin{abstract}
Crustal velocities within South Korea were estimated using GPS data and interpreted in terms of neotectonics. Twenty months of data for the seven GPS stations in South Korea were analyzed to estimate velocities relative to Taejon (DAEJ), a central region of South Korea. From the time series of horizontal position of each station, we estimated site velocities with an accuracy of $0.5 \mathrm{~mm} / \mathrm{year}$ or better mostly. The relative velocities within the Korean peninsula are very small $(\sim 1 \mathrm{~mm} /$ year $)$, convertible to strain rates in the order of $0.01 \mathrm{ppm} / \mathrm{yr}$. They indicate the Korean peninsula is likely to be tectonically more stationary than other countries in the East Asia, for example, Japan or Taiwan. The result of GPS analysis suggests a possibility that northwestward tectonic force due to the AM (Amurian plate)-PH (Philippine Sea plate) convergence affects the southeastern part of the Korean peninsula, of which the direction is curved due to internal faults in Korea, striking nearly perpendicular to the stress trend.
\end{abstract}

\section{Introduction}

Space geodetic techniques, such as GPS, have been a useful tool in investigating global plate motions (Argus and Heflin, 1995; Larson et al., 1997) or regional tectonic movements. A number of tectonic studies using GPS have been done for the East Asia covering Japan, China and Siberia (Kato et al., 1998b; Shen et al., 2000; Holt et al., 2000). Recently, Wei and Seno (1998) and Heki et al. (1999) proposed that the East Asia contained a micro continental plate called the Amurian plate (AM), based on geodetic investigations as well as regional tectonics and seismicity. Compared to other countries, however, the geodetic or neotectonic characteristics for the Korean peninsula have not been known well because of a lack of space geodetic facilities for the past decades. However, from 1998 to 2000, mostly during 2000, a nationwide GPS network has been constructed with about 70 permanent GPS stations (Park et al., 2000).

The Korean peninsula is located between North and South China Blocks and Japanese Island Arc as a part of Eurasian or Amurian continental plate. Geologically, the peninsula is composed of three Precambrian massifs, Nangrim, Gyeonggi and Yeongnam massifs; and two Paleozoic basins, Pyeongnam and Ogcheon sedimentary basins (Fig. 1). The three Precambrian basements are considered as a single tectonic unit until the early Paleozoic period, based on the patterns of regional structural lines and the age of regional metamorphism (250 Ma) (Chwae, 1998).

The ENE-trending Haeju-Weonsan Fault (HWFT) divides the peninsula into two parts. NNE-trending Jookgaryeong Fault (JFT) (Koto, 1903) is one of the first grade deep fractures in the peninsula (Chwae et al., 2000). The neotectonic

Copy right (C) The Society of Geomagnetism and Earth, Planetary and Space Sciences (SGEPSS); The Seismological Society of Japan; The Volcanological Society of Japan; The Geodetic Society of Japan; The Japanese Society for Planetary Sciences. events in the Korean peninsula can be characterized as reactivation of preexisting faults and intraplate earthquakes (Chwae et al., 1998). The JFT and Ogcheon Fault Belt (OFT) have been reactivated intermittently until the Cenozoic. The seismological focal depth of the Korean peninsula is relatively shallow. Earthquakes usually occur at about 15 to $20 \mathrm{~km}$ in depth, which indicates intraplate earthquakes are dominant in the Korean peninsula (Jun et al., 1993).

The purpose of this study is to characterize neotectonic affection for the Korean peninsula based on new GPS data from seven GPS stations of Korean GPS network.

\section{GPS Data Analysis}

We analyzed the data from seven GPS stations in Korea (Fig. 2). They are Taejon, Suwon, Kwangju, Jeonju, Taegu, Cheju and Kangreung. Taejon (DAEJ) and Suwon (SUWN) are currently participating in the International GPS Service (IGS) (IGS, 1999). Cheju (CHJU) station is located outside of the Korean peninsula. Data collected for twenty months from October 1998 to June 2000, with a roughly five-day interval, were analyzed using Bernese software V4.2. (Beutler et al., 2000). The data from June 1999 to September 1999 were excluded in this analysis because they were not available in most sites.

The double differences of carrier phase data above 15 degrees mask angle have been processed. The quasi-ionosphere free (QIF) strategy was used for L1/L2 ambiguity resolution. We estimated the baselines with L3 ionospherefree linear combination. IGS final precise ephemeris was employed as an input value of the GPS satellite orbit. Data of seven sites were simultaneously analyzed to estimate baselines, and coordinates have been estimated in the IERS Terrestrial Reference Frame (ITRF) 96 relative to our reference site DAEJ. Because we are only interested in move- 


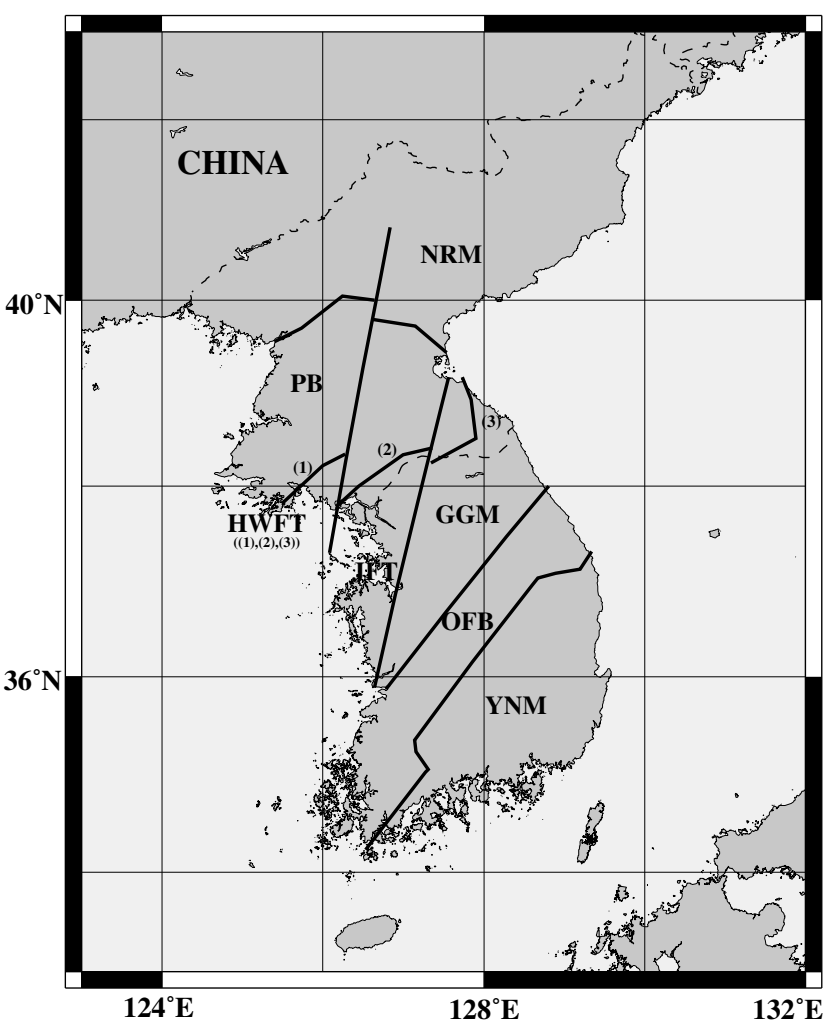

Fig. 1. Revised tectonic province map of the Korean peninsula (Chwae, 1998). NRM: Nangrim Massif, PB: Pyeongnam Basin, GGM: Gyeonggi Massif, OFB: Ogcheon Fold Belt, YNM: Yeongnam Massif, HWFT: Haeju-Weonsan Fault, JFT: Jookgaryeong Fault.

ments relative to the velocity of DAEJ in ITRF96, i.e. 29.8 $\mathrm{mm} / \mathrm{yr}$ eastward, $15.4 \mathrm{~mm} / \mathrm{yr}$ southward and $0.1 \mathrm{~mm} / \mathrm{yr}$ downward (http://lareg.ensg.ign.fr/ITRF/ ITRF96_GPS.SSC), we assumed the ITRF96 velocity at DAEJ and estimated velocities relative to it. Although fixing only one site would introduce apparent rigid network rotation, there are some indications that the velocity difference may be small (see the comparison between GPS and VLBI at Shanghai by Kato et al. (1998b) and Takahashi et al. (1999)). We neglected such effect.

\section{GPS Results and Neotectonic Interpretation}

Examples of time series of horizontal coordinates relative to DAEJ are shown in Fig. 3. The station velocities were estimated by least squares linear fitting to the time variation of the coordinates for each station. Table 1 summarizes the velocities for the seven sites with an estimated error.

The velocities for each site, except for Kangreung (KANR), are very small, ranging from 0.4 to $1.2 \mathrm{~mm} /$ year. They indicate those stations are not moving with each other significantly. A very simple preliminary strain analysis, with the baseline length changes, shows that the strain rates in the region are in the order of $0.01 \mathrm{ppm} / \mathrm{year}$. They are actually very small compared to, for example, Japan (Kato and Nakajima, 1989; Kato et al., 1998a) or Taiwan (Yu and Chen, 1994). Hence, this suggests that the Korean peninsula is tectonically more stationary than other countries in the East Asia. The values of velocities, except for the NS component of Cheju (CHJU), have a standard error of 0.5 $\mathrm{mm} /$ year or less. However, some data such as EW and NS components of SUWN, the EW of Kwangju (KWNJ), the NS of Taegu (TEGN) and CHJU show a standard error larger than the velocity value itself. A large velocity error is unavoidable due to the short data span.

Despite of the uncertainty in the velocity, we believe that the GPS velocities may give us a possibility of neotectonic implications. The GPS data were interpreted using recent geological data, about the neotectonics of the Korean peninsula (Fig. 2). Figure 2 shows the neotectonic fault map of the Korean peninsula. The southeastern part of the OFT contacted with a Mesozoic sedimentary basin shows a reactivated WNW-ESE strike-slip fault movement, which is parallel to the movement direction of the Philippine Sea plate (PH). The NE-trending OFT, mainly developed during the Paleozoic to Mesozoic, was reactivated with a right lateral strike-slip movement. The NNE-trending JFT was reactivated with a transpressional left lateral strike-slip movement. The velocity direction of TEGN is parallel to a smallscaled WNW neotectonic fault zone with a left lateral strikeslip sense which cross-cuts the Yangsan Fault (YFT). This suggests that the northwestward dynamic force due to the AM-PH convergence (Heki et al., 1999; Miyazaki and Heki, 2001) affects the southeastern Korean peninsula and reach to the YFT. It can be interpreted that the initial dynamic force from the PH is reduced by the southwest Japan, first, and then the reduced force affects the Korean peninsula.

The velocities of KWNJ and JUNJ show a pattern that the directions are curved to the northward and the magnitudes are reduced compared with the TEGN velocity. This can be interpreted that the movement direction of the Korean Peninsula have been gradually curved when the tectonic stress of the PH towards the WNW faces the JFT next to the OFT, which strike nearly perpendicular to the stress trend.

The velocity direction of CHJU site shows an apparently different pattern from those of other sites. The ESE direction of CHJU would be developed by a combination of the motions of the Eurasian plate and the PH moving toward the SE (Argus and Gordon, 1991) and NNW directions (Seno et al., 1993), respectively, in this region.

\section{Conclusions}

Based on our GPS analysis, we conclude that, (1) Strain rates within the Korean peninsula are in the order of 0.01 $\mathrm{ppm} / \mathrm{yr}$. They indicate the Korean peninsula may be tectonically more stationary than any other countries in the East Asia, for example, Japan or Taiwan. (2) The velocities indicate a possibility that the dynamic force from the $\mathrm{PH}$ is likely to affect the southeastern part of the Korean peninsula and probably reaches to the YFT. (3) The force from the $\mathrm{PH}$ in the WNW direction may be gradually curved due to internal faults in Korea, striking nearly perpendicular to the stress trend.

This study gives the GPS velocities for the Korean peninsula for the first time, but the current results and interpretation are based on the short span preliminary data. In order to advance our understanding of the neotectonic evolution of the Korean peninsula, in the future, further detailed studies will be required for the longer time span data secured from more stations. 


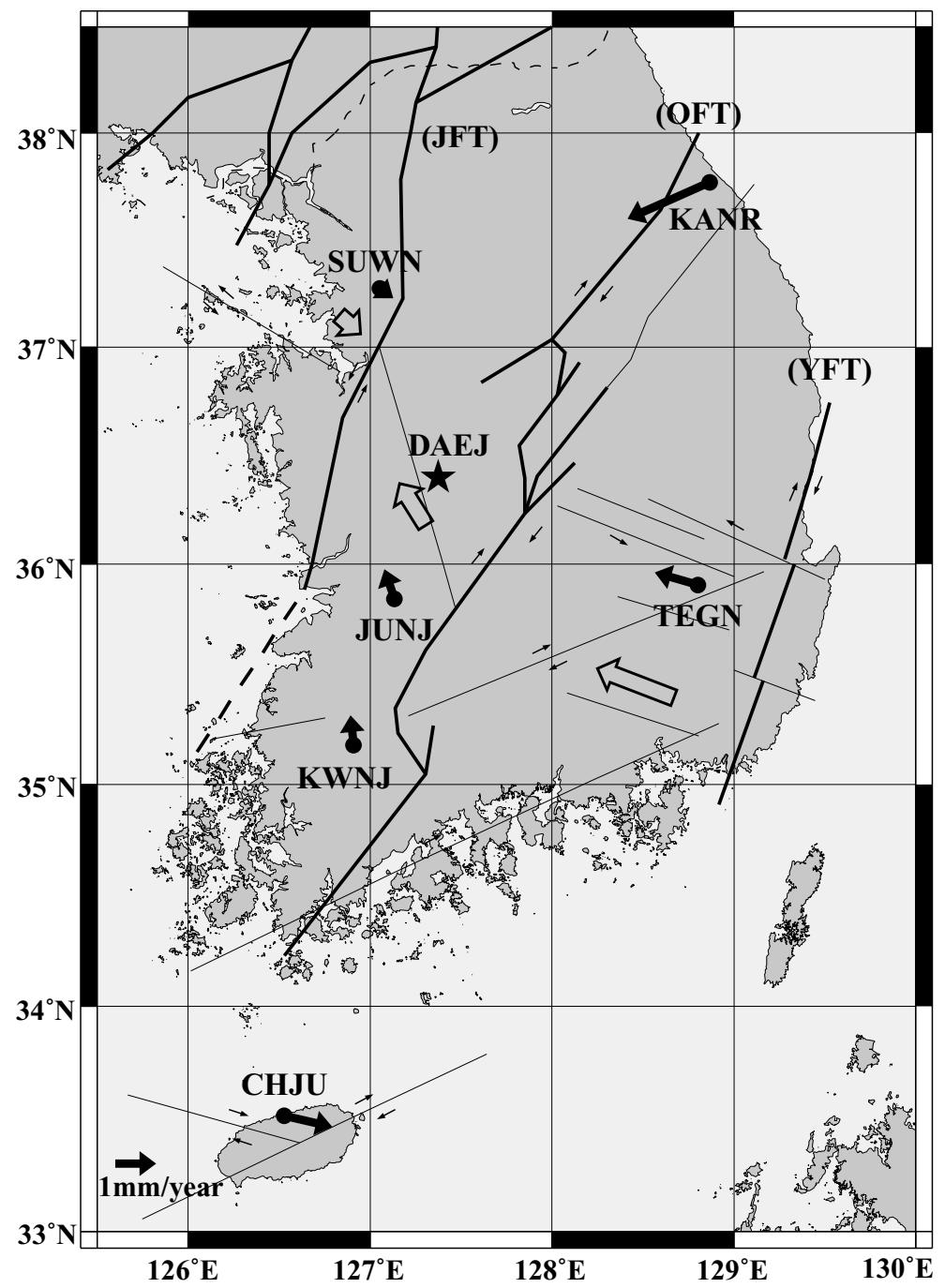

Fig. 2. Neotectonic fault map related with crustal velocities (N.B. Fixed point at Taejon). JFT: Jookgaryeong Fault, OFT: Ogcheon Fault, YFT: Yangsan Fault, thick solid line: reactivated pre-Cenozoic tectonic fault, thin solid line: reactivated fault and weak earthquake zone in southern Korean peninsula. Thick arrows are GPS velocity vectors and thin arrows are two dimensional fault movement directions; Thick blank arrows schematically display the change of the tectonic stress within Korean peninsula, which are independent of vector scale shown left-bottom in the picture.

Table 1. Site velocity relative to DAEJ with a standard error.

\begin{tabular}{|c|c|c|c|c|c|c|c|}
\hline \multicolumn{4}{|c|}{ Station } & \multicolumn{4}{|c|}{ Velocity, mm/yr } \\
\hline Name & 4 char. & Lat. & Lon. & North & East & Magnitude & Azimuth \\
\hline Taejon & DAEJ & 36.4 & 127.4 & & & & \\
\hline Suwon & SUWN & 37.3 & 127.1 & $-0.2(0.4)$ & $0.3(0.4)$ & 0.4 & 127 \\
\hline Kwangju & KWNJ & 35.2 & 126.9 & $0.7(0.5)$ & $-0.1(0.3)$ & 0.7 & 354 \\
\hline Jeonju & JUNJ & 35.8 & 127.1 & $0.7(0.3)$ & $-0.3(0.2)$ & 0.8 & 341 \\
\hline Taegu & TEGN & 35.9 & 128.8 & $0.3(0.4)$ & $-1.1(0.5)$ & 1.1 & 286 \\
\hline Cheju & СНJU & 33.5 & 126.5 & $-0.3(1.4)$ & $1.2(0.4)$ & 1.2 & 103 \\
\hline Kangreung & KANR & 37.8 & 128.9 & $-0.9(0.5)$ & $-2.0(0.5)$ & 2.2 & 246 \\
\hline
\end{tabular}

Velocity of a reference site DAEJ is fixed to zero. Values in the parentheses are standard errors of linear regression. Azimuth is measured clockwise from the north. 

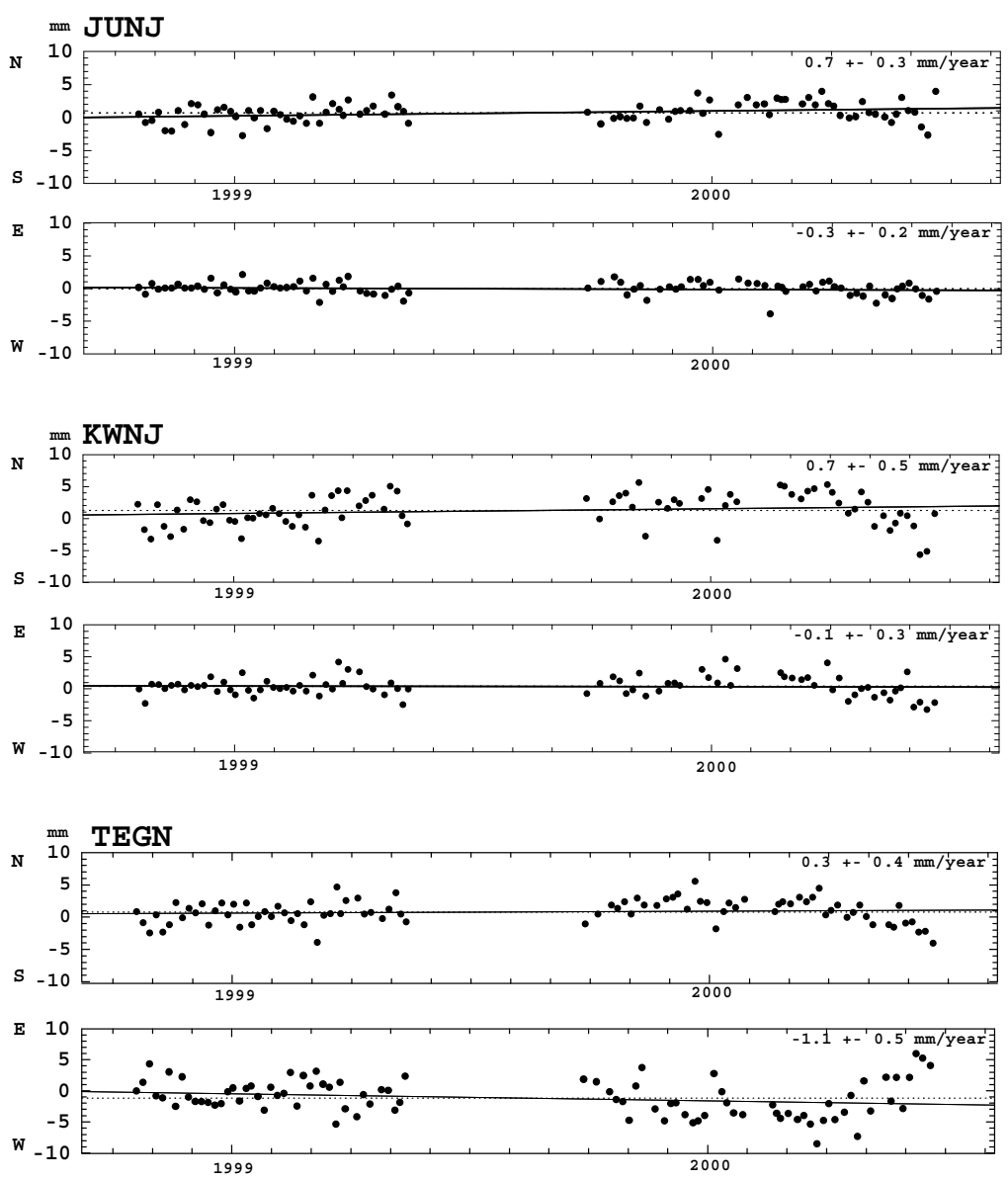

Fig. 3. Time series (solid lines) of horizontal coordinates for the selected sites: (above) Jeonju (JUNJ), (middle) Kwangju (KWNJ) and (below) Taegu (TEGN). Velocity with a standard error by linear regression is shown on the upper-right side. Taejon (DAEJ) is assumed to be fixed. The dashed lines indicate zero velocity.

Acknowledgments. The authors thank National Geography Institute of Korea for providing his GPS data. We also thank Teruyuki Kato (ERI, Univ. of Tokyo) and Chi-Ching Liu (Academica Sinica, R.O.C) for their valuable comments and suggestions. Their critical reviews improved the quality of the paper. The research was supported in part by Ministry of Science \& Technology of Korea grant N2-01-04-A-01 and KINS. A software package, Generic Mapping Tool (GMT), was used to plot the figures.

\section{References}

Argus, D. F. and R. G. Gordon, No-net rotation model of current plate velocities incorporating plate motion model NUVEL-1, Geophys. Res. Lett., 18, 2039-2042, 1991.

Argus, D. F. and H. B. Heflin, Plate motion and crustal deformation estimated with geodetic data from Global Positioning System, Geophys. Res. Lett., 22, 1973-1976, 1995.

Beutler, G., et al., Bernese GPS Software Version 4.2, Astronomical Institute, University of Berne, 2000

Chwae, U., Does the Imjingang Fold Belt cross the mid-Korean Peninsula along the demilitarized zone (DMZ) as an extension of the Sulu Belt, China?, J. Earth Planet. Sci., Nagoya Univ., 45, 41-73, 1998.

Chwae, U., et al., Final report of the re-evaluation to the design base earthquake considering the Yangsan Fault, KIGAM-98, 1-435 pp., Korea Electric Power Corporation (KEPCO), Seoul, 1998 (in English).

Chwae, U., et al., Preliminary evaluation of tectonic-scaled safety of Korean Peninsula, KAERI-CM-335-99, 1-44 pp., Ministry of Science \& Technology of Korea, Seoul, 2000 (in Korean).

Heki, K., S. Miyazaki, H. Takahashi, M. Kasahara, F. Kimata, S. Miura, N. Vasilenko, A. Ivashchenko, and K.-D. An, The Amurian Plate motion and current plate kinematics in eastern Asia, J. Geophys. Res., 104, 29147-29155, 1999.
Holt, W. E., N. Chamot-Rooke, X. Le Pichon, A. J. Haines, B. Shen-Tu, and J. Ren, Velocity field in Asia inferred from Quaternary fault slip rates and Global Positioning System observations, J. Geophys. Res., 105, 19185-19209, 2000.

IGS, GPS Tracking Network of the IGS, in IGS 1999 Directory, viii-ix pp. IGS Central Bureau, JPL, 1999.

Jun, M. S., et al., Neotectonics in and around the Korean Peninsula, KR93-(B)-14, 1-86 pp., Ministry of Science \& Technology of Korea, Seoul, 1993 (in Korean).

Kato, T. and K. Nakajima, Regional crustal movements in Japan and geodesy by space techniques, J. Geod. Soc. Japan, 35, 171-185, 1989.

Kato, T., G. S. El-Fiky, E. N. Oware, and S. Miyazaki, Crustal strains in the Japanese islands as deduced from dense GPS array, Geophys. Res. Lett., 25, 3445-3448, 1998a.

Kato, T., Y. Kotake, S. Nakao, J. Beavan, K. Hirahara, M. Okada, M. Hoshiba, O. Kamigaichi, R. B. Feir, P.-H. Park, M. D. Gerasimenko, and M. Kasahara, Initial results from WING, the continuous GPS network in the western Pacific area, Geophys. Res. Lett., 25, 369-372, 1998b.

Koto, B., An orographic stretch of Korea, J. Coll. Sci. Imp. Univ. Tokyo, 19, Art. 1, 1903 (in Japanese).

Larson, K. M., J. T. Freymueller, and S. Philipsen, Global plate velocities from the Global Positioning System, J. Geophys. Res., 102, 9961-9981, 1997.

Miyazaki, S. and K. Heki, Crustal velocity field of southwest Japan: Subduction and arc-arc collision, J. Geophys. Res., 106, 4305-4326, 2001.

Park, P.-H., et al., Establishment and Management of GPS Network for Crustal Deformation Monitoring in Korea, N2-01-04-A-01, 48-64 pp., Ministry of Science \& Technology of Korea, Seoul, 2000 (in Korean).

Seno, T., S. Stein, and A. Gripp, A model for the motion of the Philippine sea consistent with NUVEL-1 and Geological data, J. Geophys. Res., 98, 17941-17948, 1993.

Shen, Z.-K., C. Zhao, A. Yin, Y. Li, D. D. Jackson, P. Fang, and D. Dong, 
Contemporary crustal deformation in east Asia constrained by Global Positioning System measurements, J. Geophys. Res., 105, 5721-5734, 2000.

Takahashi, H., M. Kasahara, F. Kimata, S. Miura, K. Heki, T. Seno, T. Kato, N. Vasilenko, A. Ivashchenko, V. Bahtiarov, V. Levin, E. Gordeev, F. Korchagin, and M. Gerasimenko, Velocity field of around the Sea of Okhotsk and Sea of Japan regions determined from a new continuous GPS network data, Geophys. Res. Lett., 26, 2533-2536, 1999.

Wei, D.-P. and T. Seno, Determination of the Amurian Plate motion, in Mantle Dynamics and Plate Interactions in East Asia, Geodyn. Ser., vol. 27, edited by M. F. J. Flower, et al., 337 pp., AGU, Washington, D.C., 1998.

Yu, S.-B. and H.-Y. Chen, Global Positioning System measurements of crustal deformation in the Taiwan Arc-Continent Collision Zone, Terrestrial, Atmospheric and Oceanic Sciences, 5, 477-498, 1994.

P.-H. Park (e-mail: phpark@kao.re.kr), U. Chwae (e-mail: chwae@ kigam.re.kr), Y.-W. Ahn (e-mail: ahnyw@hotmail.com), and K.-H. Choi (e-mail: khchoi@galaxy.yonsei.ac.kr) 